\title{
Investigation of The Effects of Eccentricity on Induction Motor via Multi-Resolution Wavelet Analysis
}

\author{
Abdullah Polat ${ }^{1}$ iD, Abdurrahman Yılmaz² ${ }^{\text {iD }}$, Lale T. Ergene' \\ 'Department of Electrical Engineering, İstanbul Technical University School of Engineering, İstanbul, Turkey \\ 2Department of Control and Automation Engineering, İstanbul Technical University School of Engineering, İstanbul, Turkey
}

Cite this article as: A. Polat, A. Y.lmaz, L.T. Ergene, "Investigation of The Effects of Eccentricity on Induction Motor via Multi-Resolution Wavelet Analysis", Electrica, vol. 18, no: 2, pp. 187-197, 2018.

\section{ABSTRACT}

In this paper, a $2.2 \mathrm{~kW}$ squirrel cage induction motor having different degrees of static eccentricity is analyzed for fault detection using multi-resolution wavelet analysis (MRWA). The reference squirrel cage induction motor was simulated by using finite element method (FEM) and verified with the test results for the reference. Multi-resolution wavelet analysis was applied to decompose the high frequency components of flux density and current of the induction motor with different levels of eccenctricity. The effects of these components on the torque and vibration characteristics were also examined. The results show that MRWA could be a good alternative to fast fourier transform (FFT) in detecting air gap eccentricity in motors.

Keywords: Induction motor, eccentricity, finite element method, multi-resolution wavelet analysis, diagnosis

\section{Corresponding Author:}

Lale Tükenmez Ergene

E-mail:

ergenel@itu.edu.tr

Received: 02.01 .2018

Accepted: 16.03 .2018

(c) Copyright 2018 by Electrica

Available online at

http://electrica.istanbul.edu.tr

DOI: 10.5152/iujeee.2018.1821

\section{Introduction}

Induction motors are preferred in many applications because of their ease of maintenance, affordable price and robustness. Moreover squirrel cage induction motors are currently dominating the market since they can even be operated under faulty conditions [1, 2]. Motor faults are mainly caused by the windings, rotor, bearings, and air gap eccentricity and they have been analyzed and published by different researchers for many years [3, 4]. In this paper, the focus will be on faults cused by air gap eccentricity.

Various studies have been conducted on eccentricity faults and its detection since the first quarter of the $20^{\text {th }}$ century. In the early years, researchers were focused on the mechanical reasons leading to faults and the magnetic and mechanical problems resulting from faults. Dating from the 1970s, different diagnostic methods have been developed to predict faults that might happen due to eccentricity. There are many diagnostic methods in the literature such as electromagnetic field monitoring, noise, vibrations, temperature measurements, and infrared recognition, etc. [4-6]. However, vibrations and motor current signals are predominant to detect eccentricity faults and have been preferred in applications [7]. The analysis of motor current to diagnose faults has been the subject of much research in the 1990s. The researchers addressed the modeling of the dynamic and/or static eccentricity faults with different eccentricity levels for different types of motors and investigated the motor parameters [8-10]. Finite element method (FEM) based programs have routinely been utilized to model such eccentricity faults. The work on eccentricity harmonics were the basis of the studies in the 2000s [11, 12].

Until today, many studies have been conducted to detect faults in induction motors. One of the simplest procedures applied to fault detection is Fast Fourier Transforming (FFT) on the stator phase currents due to the fact that it includes many of the motor harmonics whose properties on faulty conditions (this is a fragment - finish the sentence please - Revise for clarity) [13]. A challenge can occur while using FFT analysis because the signals to be analyzed con- 
tain many non-stationary and transitory components. That's why, for fault detection or estimation, wavelet analysis based methods have recently been preferred. Three basic and significant motivations for using the new generation methodologies (including wavelet analysis) are listed as follows [14]:

- Requirement of non-stationary signal observation;

- Necessity of precise fault detection by acquired features even in light-load conditions;

- Challenge in fault detection by FFT feature extraction under harmonics caused by power electronic converters supplying induction motors.

Wavelet analysis is a promising technique that provides a powerful tool for fault analysis and has been used since the late 1980s. Wavelet transformation gives both time and time frequency analysis with multiresolution characteristics. It is possible to obtain the desired part of the signal in both time and frequency domains. Therefore, fault diagnosis based on wavelet analysis is becoming a trend for electrical machine designers [15].

The word "wavelet" was firstly used in the literature at the beginning of the 20th century and many related studies which contribute to wavelet theory have been conducted till the end of 1980s. The main algorithm of the theory is based on Mallat's work from 1988 [16].

Wavelet analysis in fault detection of electrical machines first started to be used from the mid-1990s. The current and vibration signals in healthy and faulty situations have been investigated using different wavelet analysis methods, e.g. Discrete Wavelet Transform (DWT), Continuous Wavelet Transform (CWT), Wavelet Packet Transform (WPT) and MRWA] to determine the faults caused by rotor bar failures, switching errors in inverter-fed machines, and eccentricity [17-21]. The research on fault diagnosis has gained a different perspective owing to the combined use of wavelet analysis and artificial neural network methods from the 2000s onwards [22]. These advancements are currently being performed in the work on PMSM and BLDC electric motors, which are becoming widespread, as well as for 3-phase asynchronous motors, which are widely used in the industry [23]. As a result, wavelet analysis is commonly used in fault diagnosis, online monitoring and protection areas.

In this study, an induction motor was simulated using a two dimensional (2D) finite-element analysis. The stator current was analyzed by means of the MRWA via MATLAB/Wavelet Toolbox. In the literature, there is no approach for the eccentricity failures with the wavelet analysis, they were investigated from either the tests or FEM based results $[3,9]$. The results were compared in terms of machine performance characteristics such as current, flux density, torque etc. Simulations were also compared with experimental results, and were used to verify the validity of the approach.

\section{Dynamic Modeling of Induction Motor}

\section{Air Gap Eccentricity in Induction Motor}

Eccentricity is defined as the condition of unequal air gap that exists between the stator and rotor. There are three types of eccentricity: static, dynamic and mixed of which the later is the combination of the previous two.

The stator center is located at the first axis and the rotor center is located at the second axis as shown in Figure 1. The eccentricity is named as dynamic or static eccentricity if the center of rotation is at the first or second axis respectively. The rotation axis can be placed anywhere between the first and second axis. Such a situation is called mixed eccentricity [3]. For correctly operating motors (healthy case), however, the center of the rotor and stator must be coincident.

One of the reasons for non-uniform air gap of an induction motor is due to manufacturing defects. The stator bore and/or rotor face may not be manufactured in 'a perfectly cylindrical shape'. Another reason is bad mechanical bearing accouplement as the center of rotor and stator may not be concentric. Beside these reasons, there are other causes of eccentricity such as bearing wear, rotor shaft bending, or resonance at critical speeds, etc.

\section{Finite Element Method (FEM)}

The use of numerical models to analyze electrical machines for the purpose of calculating electric and magnetic fields is rapidly changing. When the difficulty of performing analytical solutions due to the complex structures of electrical machines and nonlinear characteristics of used materials is considered, it is clearly comprehended why numerical solutions are frequently used.

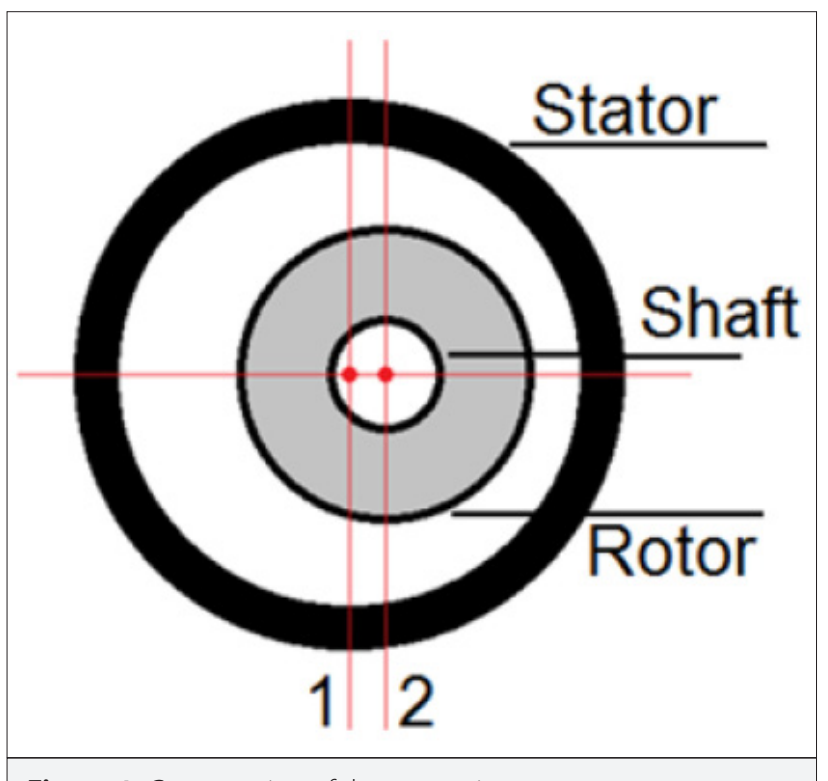

Figure 1. Cross-section of the eccentric motor 
Finite element method is one of the most suitable numerical methods for this purpose since it is preferred to solve problems that are time dependent or include nonhomogeneous, directional and nonlinear components where analytical methods are inadequate [24]. The unknown parameters in the finite number are expressed in terms of known parameters of the system in FEM based analysis. The procedure to solve a problem using FEM is as follows;

- Separate solution region to finite elements;

- Write fundamental equations for each element;

- Combine all elements in solution region;

- Solve achieved equation set.

Finite element method simulations are principally based on the solutions of Maxwell equations including the expressions of magnetic flux density, magnetic field intensity, electrical flux density and current density.

To simplify the solution of field problems, the vector potential $\mathbf{A}$ is used in the calculations instead of the field. The relation between magnetic vector potential and magnetic flux density can be given as shown below.

$B=\nabla \times \mathbf{A}$

Flux density components of the air gap in the Cartesian coordinates are expressed as follows;

$B_{x}=\frac{\partial A_{z}}{\partial y}-\frac{\partial A_{y}}{\partial z}$

$B_{y}=\frac{\partial A_{x}}{\partial z}-\frac{\partial A_{z}}{\partial x}$

$B_{z}=\frac{\partial A_{y}}{\partial x}-\frac{\partial A_{x}}{\partial y}$

2-D finite element analysis was chosen for electrical machines since it decreases the computation memory requirement and reduces computational time. In this case, the components in $z$ direction are assumed as zero and only $x$ and $y$ directions are used for magnetic vector potential $A$. The magnetic flux density is stated in two dimensional space as shown below.

$B_{x}=\frac{\partial A_{z}}{\partial y} \quad B_{y}=-\frac{\partial A_{z}}{\partial x} \quad B_{z}=0$

For the two dimensional model, the relationship between the magnetic vector potential and current density due to the Maxwell Equation is given as:

$\frac{\partial}{\partial \mathrm{x}}\left(\frac{1}{\mu} \frac{\partial \mathbf{A}}{\partial x}\right)+\frac{\partial}{\partial \mathrm{y}}\left(\frac{1}{\mu} \frac{\partial \mathbf{A}}{\partial y}\right)=-\mathbf{J}_{\mathbf{S}}$

where $\mathbf{A}, \boldsymbol{\mu}$ and $\mathbf{J}_{\mathbf{s}}$ are magnetic vector potential, magnetic permeability and current density respectively.
A two-dimensional problem region is bounded point by point and the points are joined with line segments. More points and consequently smaller line segments should be preferred in order to represent the real boundary accurately. The density of network elements affects the accuracy of the solution and the element density is scattered into fields with respect to its structure [24]. Smaller and more frequent elements are used in the regions with small radius of curvature where the field values change rapidly, while larger and less frequent elements are preferred in the regions with larger radius of curvature as in Figure 2.

Boundary conditions need to be assigned carefully in order to solve electromagnetic field problems that affect accuracy and precision. There are three type of the boundary conditions for the solution of electromagnetic problems: Neumann, Dirichlet and mixed boundary conditions. Neumann boundary conditions are defined by setting all point values of the potential of the boundary to the specified value, and only interior nodes are unknowns. Dirichlet boundary condition can be applied by using additional equations at the boundary which requires boundary point values to be equal to the nearest interior neighbor. In this study, the boundary condition of the motor was set to zero by applying Dirichlet boundary condition.

\section{Finite Element Method Simulation Results}

The squirrel cage induction motor used in this study had the following ratings: 3 phase, $2.2 \mathrm{~kW}, 4$ poles, 36 slots, 28 rotor bars, $50 \mathrm{~Hz}, 400 \mathrm{~V}, 5 \mathrm{~A}, 1440 \mathrm{~min}^{-1}$. Stator windings were connected using delta connection. The different degrees of static eccentric cases of the induction motor were simulated and compared with the results of a healthy motor by using FEM based commercial software FLUX 2D.

The induction motor simulation results were obtained under rated operating conditions with no asymmetry. Figure 3, 4 show the equi-flux lines for a two-pole pairs induction motor and radial/tangential components of the flux density in the middle of the air gap, respectively.

In Figure 5, the color spectrum of flux density was obtained as well as equi-flux lines.

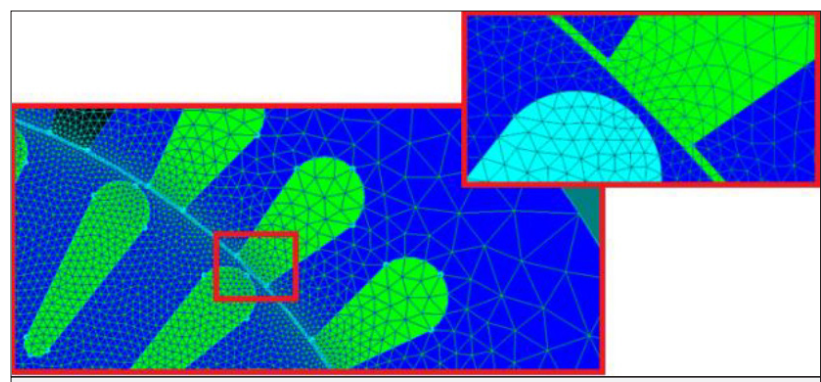

Figure 2. Mesh Topology 


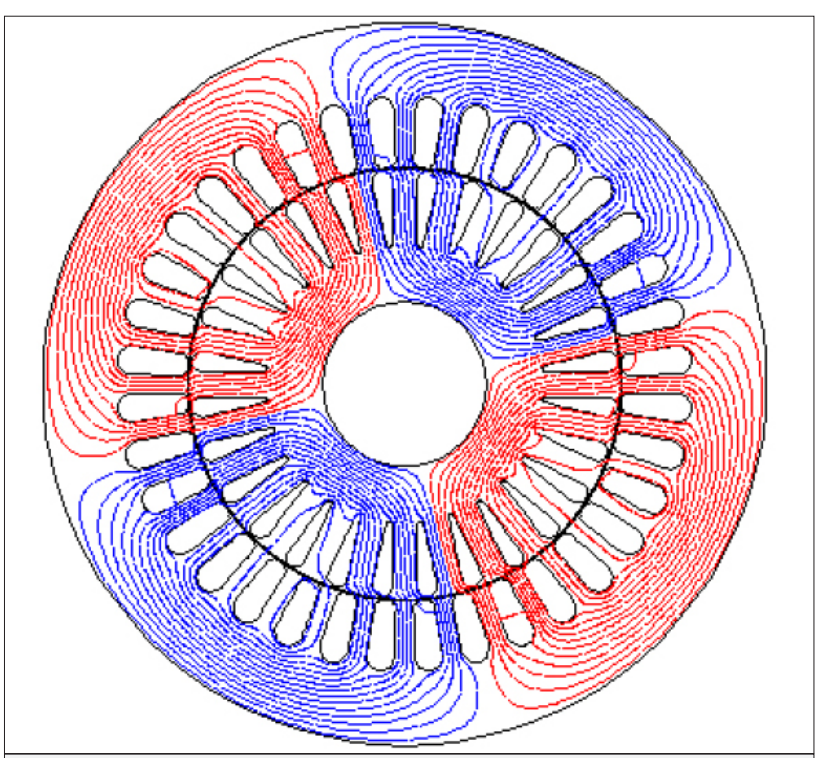

Figure 3. Equi-flux lines of healthy motor case

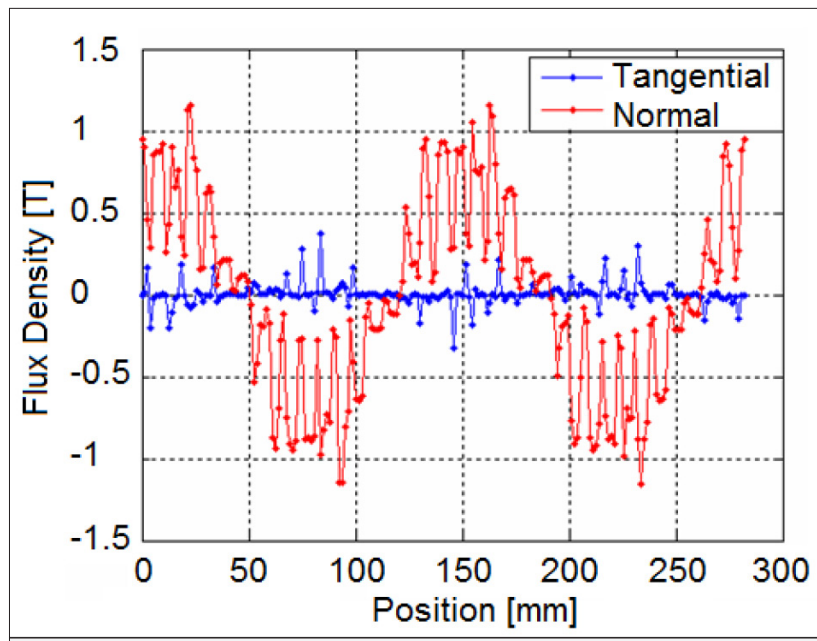

Figure 4. Air gap flux density radial-tangential components, the healthy motor case

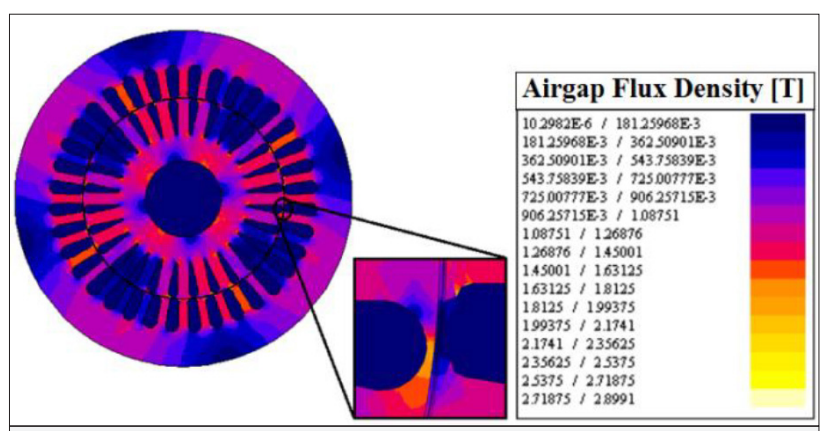

Figure 5. Color spectrum of flux density \& air gap detail

The achieved experimental results using the test motor verified the simulation studies for healthy condition since the difference between the simulation and experimental results in terms of rated current, rated torque, and output power was below $1 \%$. The obtained motor characteristics for the healthy condition were utilized in the analysis of asymmetrical operating conditions where the models with different degrees of static eccentricity were produced.

Eccentric motor characteristics were investigated by defining the rotor and its rotation axes seperately. Asymmetrical conditions were obtained by offsetting the rotor and its rotation axes by $10 \%, 30 \%, 50 \%$ and $80 \%$, respectively. The geometry of the highest degree of the eccentric condition (80\%) is given in Figure 6.

\section{Overview of Wavelet Analysis}

In this section, wavelet transformation for discrete signals is explained briefly. The easy localization of the signal in the time and frequency plane in the wavelet analysis makes the method suitable for the analysis of non-stationary signals and a good alternative to conventional Short Time Fourier Transform (STFT).

In classical approaches, the frequency components of the signal are determined and it is assumed that the components are identical in each part of the signal. However, this approach may not always be valid. The idea of analyzing the signal in short time windows was revealed to eliminate this deficiency and was successfully applied by Gabor in 1946. However, the window size affects the accuracy of the application since it remains constant. The frequency resolution is better when the window size is large. So the size of the window is very important in order to get a more accurate result in terms of frequency or time components from the analyzed signal parts.

Wavelet analysis is based on a windowing technique for variable-sized regions. Moreover, it allows to get results in both high and low frequencies at short and long time intervals respectively.

Fourier analysis is achieved by means of Fourier Transformation which is the sum of the multiplications of the signal and complex exponential multipliers. The purpose of Fourier transformation is to calculate Fourier coefficients. Thus, the signal is divided into components each having a separate amplitude and frequency. Similarly, the wavelet function is shifted and summed over time after being multiplied by a scaling factor in wavelet analysis. The mathematical expression is,

$\psi_{a, b}(t)=\frac{1}{\sqrt{a}} \psi\left(\frac{t-b}{a}\right)$

where ' $a$ ' and ' $b$ ' are scaling and shifting parameters respectively. The translation parameter ' $b$ ' refers to the position of the wave in time and the scale parameter ' $a$ ' refers to the change in different frequencies. In this context, the following conditions must be satisfied. 


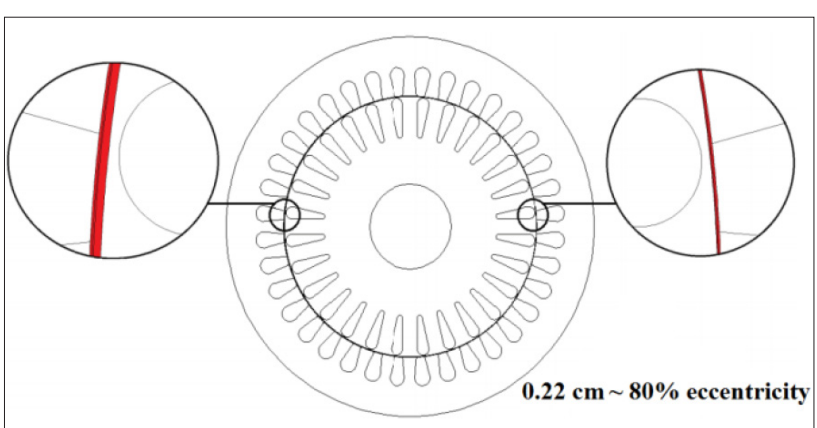

Figure 6. The geometry of static eccentric motor

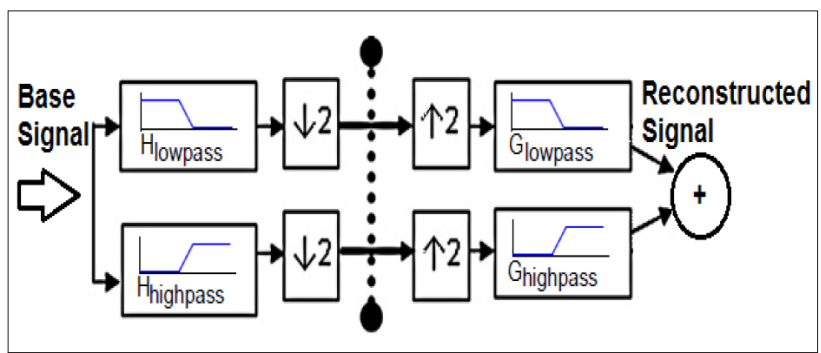

Figure 7. Mallat's algorithm demonstration

$$
\begin{aligned}
& (\$) \psi(x) d x=0 \\
& \int_{-\infty}^{\infty} \psi^{2}(x) d x=1 \\
& \int_{0}^{\infty} \frac{|\psi(\omega)|^{2}}{|\omega|} d \omega=\int_{-\infty}^{0} \frac{|\psi(\omega)|^{2}}{|\omega|} d \omega=C_{\psi}<+\infty
\end{aligned}
$$

Energy conservation and completeness are guaranteed by a real wavelet transformation on the weak admissibility condition is satisfied.

A wavelet is like an oscillation with an amplitude that starts at zero, increases to its maximum, and then goes back to zero. Wavelet analysis is generally focused in time unlike Fourier transformation for the decomposition of a signal. While the Fourier transformation using sine functions is only shown in frequency domain, wavelet provides an analysis of the signal in both time and frequency domains.

In practice, DWT transforms discrete signals to discrete coefficients in the wavelet domain. This transformation is basically a sampled version of CWT [25]. The length of the signal satisfies $\mathrm{N}=2 \mathrm{~J}$ for a positive $\mathrm{J}$ in the case of DWT. The transformation can be performed efficiently using Mallat's algorithm [16]. The decomposition of the signal into different scales can be considered as different frequency bands.
The high-pass (HP) and low-pass (LP) filters utilized in the algorithm are chosen due to the mother wavelet in use. The outputs of the LP filters are assigned as the approximation coefficients, and the outputs of the HP filters are assigned to the detail coefficients.

Each decomposition level of the produced signal by the filters covers the half of the frequency band. This helps to increase the frequency resolution so that the frequency uncertainty can be reduced. Hence, each filter output can be reduced by a factor of two by using Nyquist's theorem. Frequency resolution gives good outputs at low frequencies. However, time resolution becomes better at high frequencies. The number of decomposition steps should be decided by considering the properties of the signal.

One of the discrete wavelet transformations is MRWA. Wavelet filters, called $H$ and $G$, are utilized in MRWA for decomposition and reconstruction of the signal to be analyzed. Figure 7 shows a one-level fundamental procedure of the decomposition and reconstruction of the signal. It should be noted that it may not be possible to obtain the desired frequency region by wavelet decomposition at once, so it can be applied repeatedly.

\section{Methodology}

The decomposed signal which was achieved by wavelet analysis needed to be reprocessed according to the desired frequency band since the effects of the fundamental and high frequency harmonic components on the flux, current and torque characteristics were being investigated in this research. Although, as explained previously, using Mallat's algorithm gave the fundamental component of the signal and the algorithm was not able to completely show the effects of high frequency components. The characteristic including fundamental component of the signal was expressed in the approximation $a_{3^{3}}$, whereas the details $d_{1}, d_{2}$ and $d_{3}$ did not represent the highest frequency harmonic components as in Figure 8. Therefore, the algorithm needed to be iterated again to decompose $d_{1}$ and $d_{2}$. This process helped to observe the effects of high frequency harmonic components separately.

In this direction, the decomposition process seen in Figure 9 was performed and the signals in the frequency range $7 f_{1}-8 f_{1}$ which belong to the harmonic components was compared for both healthy and faulty cases.

In this work, Daubechies-25 (Db-25) wavelet filter is used in all decompositions. An example of $\mathrm{Db}$ scaled and wavelet functions are taken from MATLAB (Figure 10).

\section{Simulation Results}

A set of tests are applied to achieve a dynamic model of the induction motor. MRWA is utilized in the analysis of some performance characteristics such as air gap flux density, current and torque. 

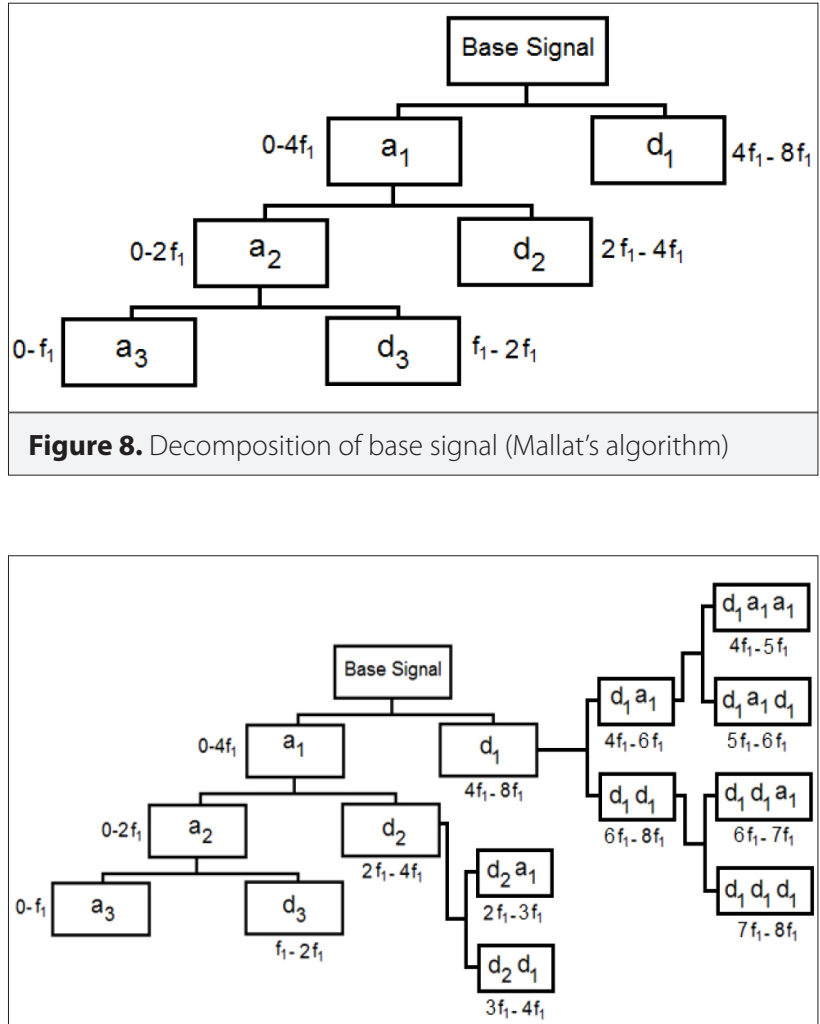

Figure 9. Decomposition of base signal (determined strategy)

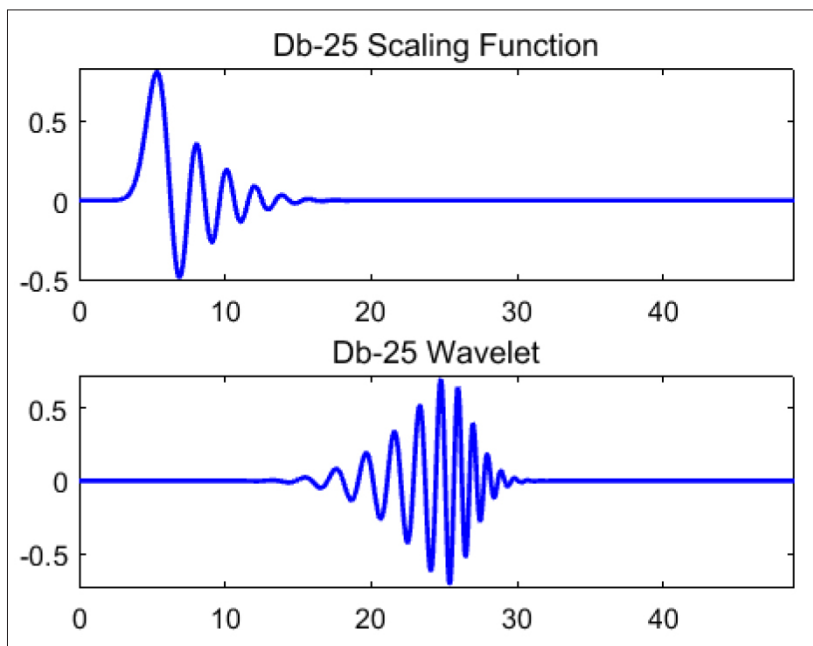

Figure 10. Daubechies-25 scaling function and its wavelet

The current and torque characteristics are obtained for the faulty (with static eccentricity) models and healthy model by using the finite elements method (FEM). In this study, wavelet analysis is used to determine how the fundamental component and high frequency components of some parameters such as flux density, torque and current were going to change in the case of eccentricity.

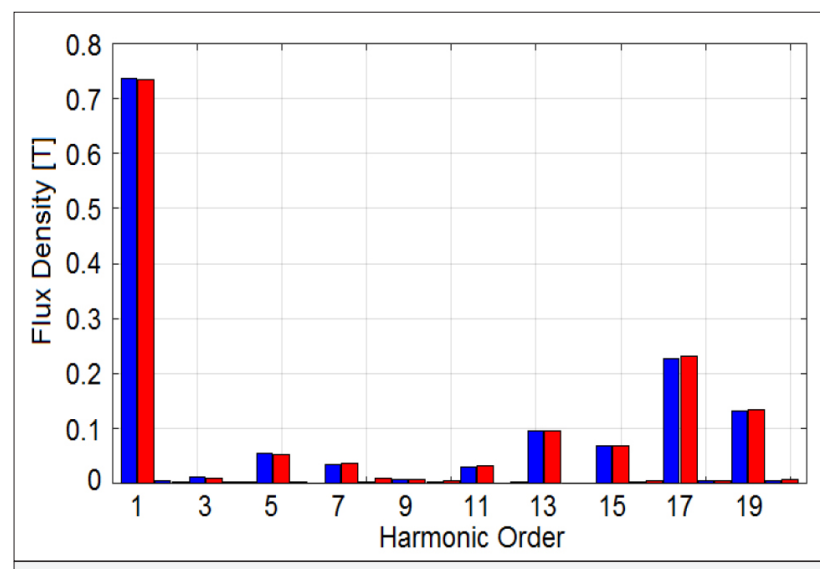

Figure 11. Comparison of normal component of air gap flux density spectrum for the healthy and $50 \%$ eccentric motors

Table 1. Comparison of air gap flux density for the healthy and eccentric induction motor

\begin{tabular}{llll}
\hline $\begin{array}{l}\text { Harmonic } \\
\text { Order }\end{array}$ & $\begin{array}{l}\mathrm{B}_{\text {gap }}[\mathrm{T}] \\
\text { (Healthy) }\end{array}$ & $\begin{array}{l}\mathrm{B}_{\text {gap }}[\mathrm{T}] \\
\text { (50 SE) }\end{array}$ & $\boldsymbol{\varepsilon}[\%]$ \\
\hline 7 & 0.03532 & 0.03623 & 2.49 \\
\hline 11 & 0.02994 & 0.03273 & 8.502 \\
\hline 17 & 0.22724 & 0.23130 & 1.758 \\
\hline 19 & 0.13133 & 0.13371 & 1.779 \\
\hline
\end{tabular}

\section{Flux Results}

The harmonics components of the reference motor are obtained by using Fourier decomposition [3, 9]. The amplitudes of the basic harmonic components of the reference motor are given in Table 1. The $7^{\text {th }}$ and $11^{\text {th }}$ belt harmonics and $17^{\text {th }}$ and $19^{\text {th }}$ space harmonics in the spectrum are increased with the increased eccentricity.Fourier analysis gave the amplitude of the harmonic components in the frequency band as seen in Figure 11 (the blue bars show healthy conditions and the red bars show the eccentric conditions).

As seen in Figure 12, the positions where the flux density took its largest and lowest values varied with respect to fault degrees. The small windows have been identified as ' $a$ ' and ' $b$ ' in Figure 12 to show this inconsistency.

For instance, the largest flux value in the window 'a' occurred for the model with $80 \%$ static eccentricity whereas the largest flux value in the window ' $b$ ' belonged to the healthy model as shown in Figure 13 respectively.

Besides the above mentioned results, the simulation results of the flux density for the healthy and eccentric conditions were 


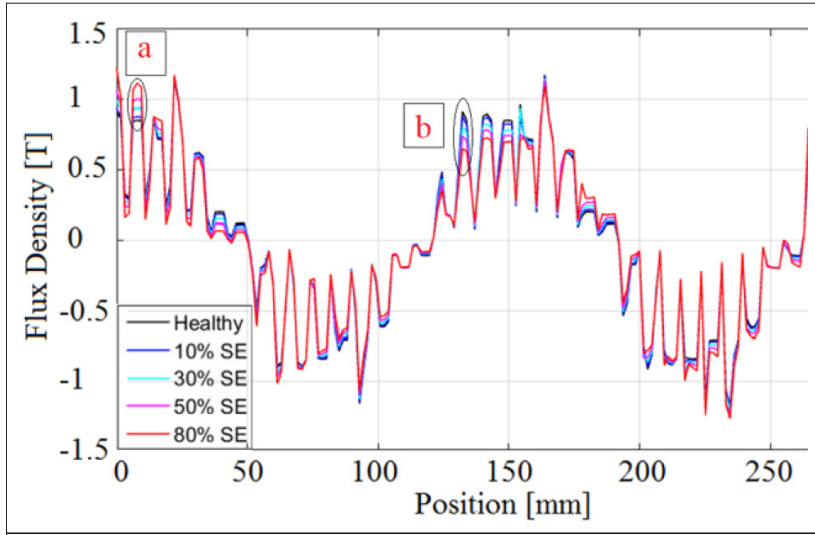

Figure 12. Radial flux density variations in the air gap for different cases
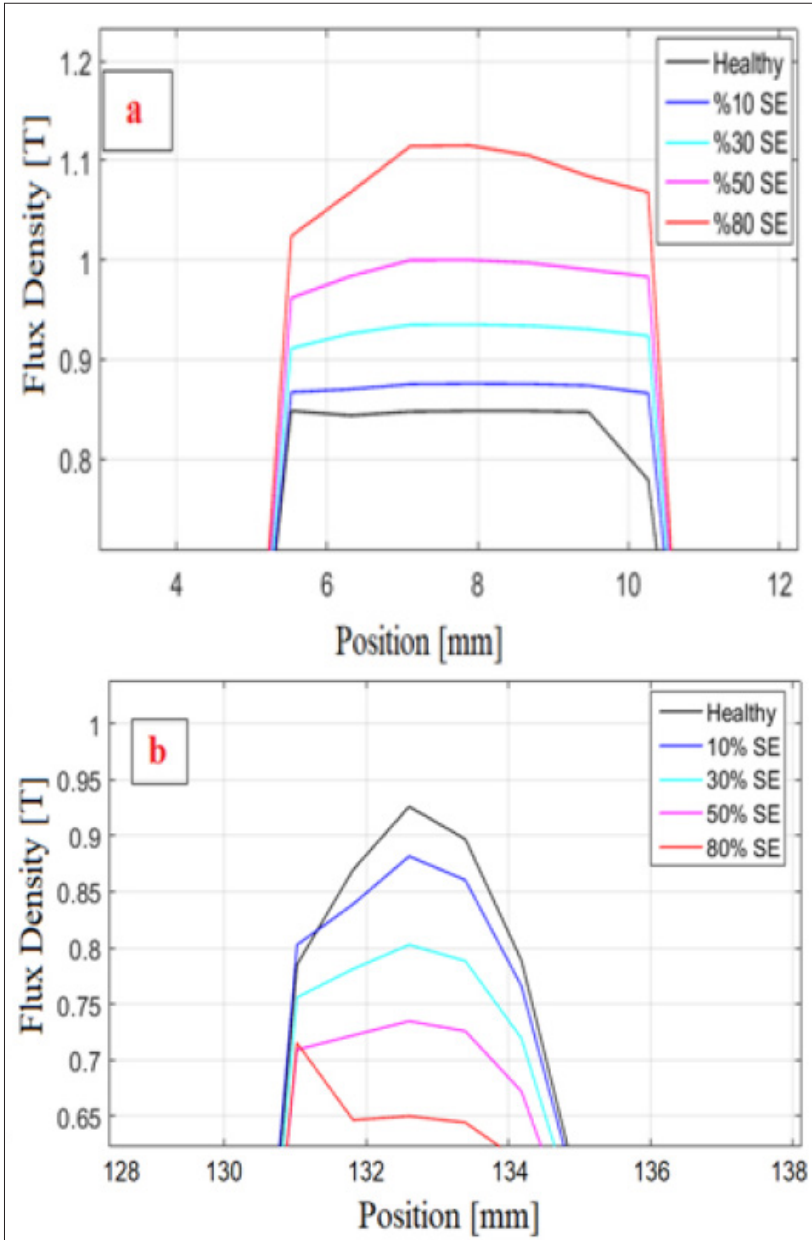

Figure 13. a,b. The detail of flux density for healthy and eccentric conditions (referring Figure 12)

decomposed by using wavelet analysis and the flux characteristics of the fundamental components were plotted comparatively as shown in Figure 14 and given in Table 2.

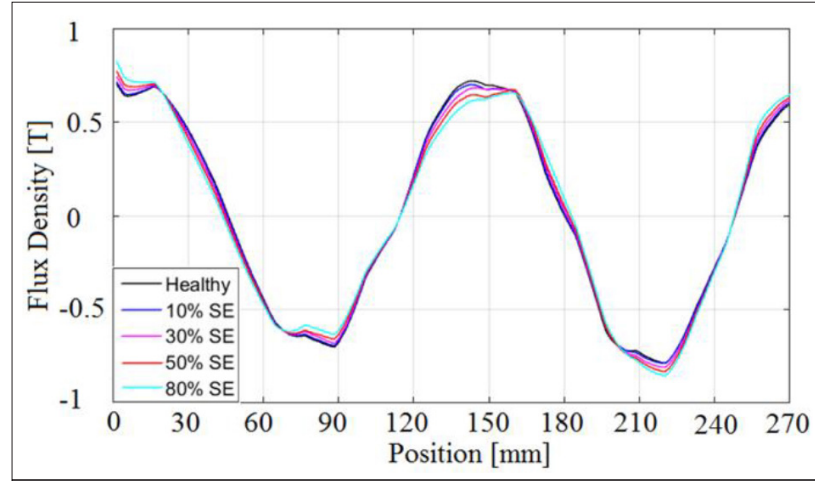

Figure 14. Fundamental components of the flux density for healthy and eccentric motors

Table 2. Flux density values for the healthy and eccentric motors

\begin{tabular}{|c|c|c|c|c|c|}
\hline & \multicolumn{5}{|c|}{ Fundamental Component } \\
\hline & & $10 \%$ & $30 \%$ & $50 \%$ & $80 \%$ \\
\hline & Healthy & SE & SE & SE & SE \\
\hline Flux Density [T] & 0.529 & 0.528 & 0.525 & 0.524 & 0.523 \\
\hline \multirow[t]{4}{*}{ Error [\%] } & - & -0.23 & -0.85 & -1.04 & -1.15 \\
\hline & \multicolumn{5}{|c|}{ Harmonic Components } \\
\hline & & $10 \%$ & $30 \%$ & $50 \%$ & $80 \%$ \\
\hline & Healthy & SE & SE & SE & SE \\
\hline Flux Density $[\mathrm{T}]$ & 0.066 & 0.068 & 0.072 & 0.079 & 0.089 \\
\hline Error[\%] & - & 3.52 & 8.37 & 16.62 & 26.01 \\
\hline
\end{tabular}

The consistency between FFT analysis and MRWA results showed the validity of MRWA results. The effects of high frequency components was also clearly seen with an increase of $26 \%$ in MRWA results.

\section{Current Results}

The current characteristics for the healthy motor obtained via simulation study are given in Figure 15.

The steady-state current signal is taken between 0.1 to $0.175 \mathrm{~s}$ of the current characteristic given in Fig 15 to analyze (Figure 16).

Based on the strategy described above, the current values of the fundamental component and high frequency components are obtained. The current characteristics after decomposition is shown broadly in Figure 17.

$0-f_{1}$ fundamental component and $7 f_{1}-8 f_{1}$ high frequency component intervals are separately examined and the interval including the fundemantal component of the current characteristic is shown in Figure 18. 


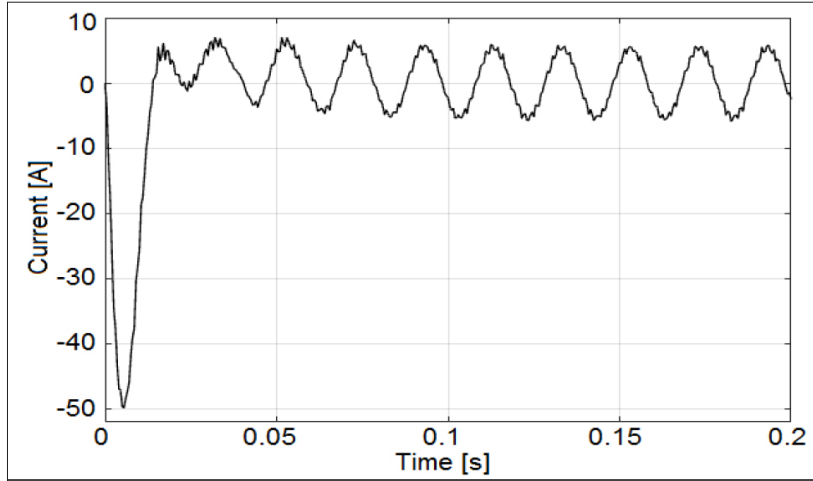

Figure 15. Current characteristic for the healthy motor (Transient)

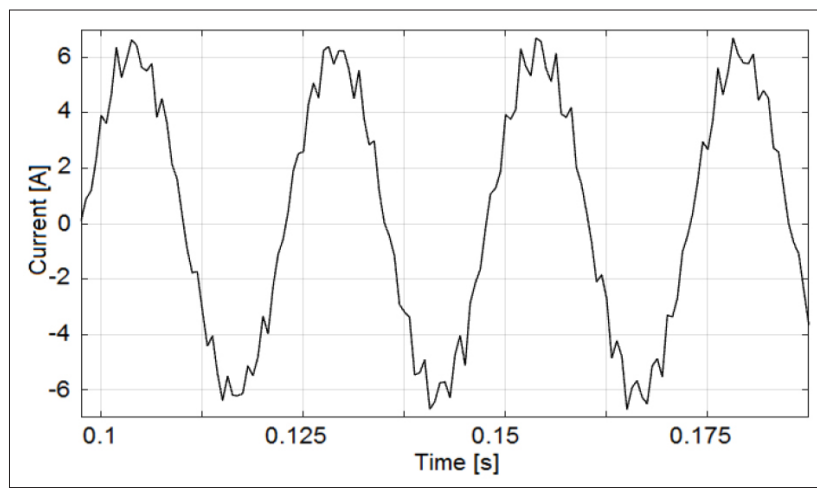

Figure 16. Current characteristics for the healthy motor (Steady-State)

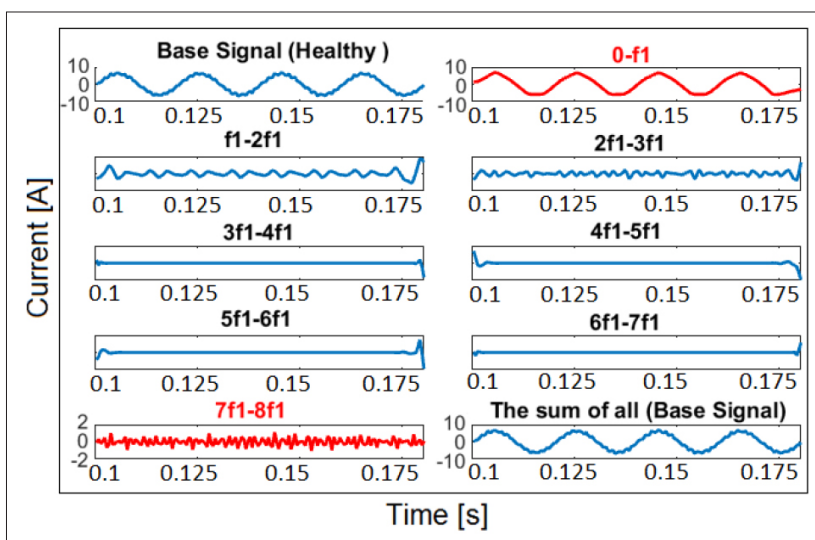

Figure 17. The decomposed current characteristics

The expected increase in the fundamental component is observed in the stator current with the increasing eccentricity as given in Table 3. Additionally, the components that distort the sinusoidal form of the current signal caused by high frequency components increased up to $5 \%$.

\section{Torque Results}

A similar approach is applied to the torque signal given in Figure 19 for the healthy condition. Wavelet analysis is employed and the effects of the decomposed high frequency components under different failure levels are obtained.

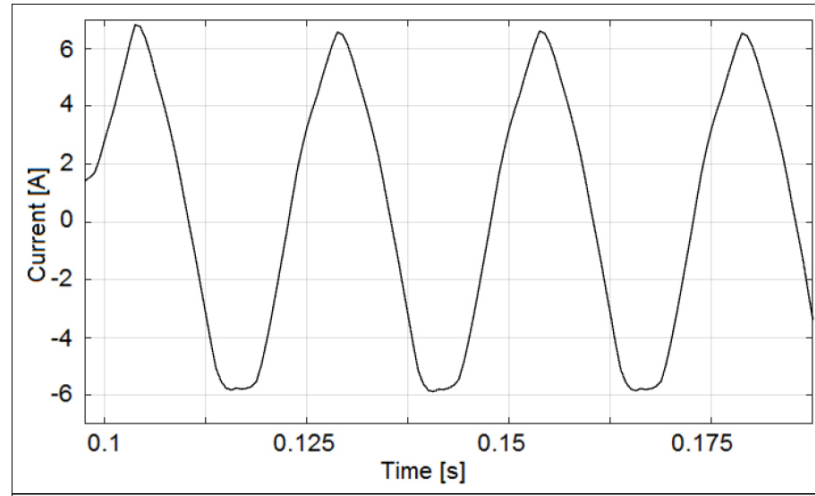

Figure 18. Fundamental component of current

Table 3. Current values for healthy and eccentric conditions (SE: Static Eccentricity)

\begin{tabular}{lccccc}
\hline & \multicolumn{5}{c}{ Fundamental Component } \\
\cline { 2 - 6 } & Healthy & $\mathbf{1 0 \%}$ SE & $\mathbf{3 0 \% ~ S E}$ & $\mathbf{5 0 \% ~ S E ~}$ & $\mathbf{8 0 \% ~ S E}$ \\
\hline Current [A] & 4.383 & 4.39 & 4.4 & 4.4 & 4.40 \\
\hline Error[\%] & - & 0.18 & 0.33 & 0.37 & 0.39 \\
\hline & \multicolumn{5}{c}{ Harmonic Components } \\
\cline { 2 - 6 } & Healthy & $\mathbf{1 0 \% ~ S E}$ & $\mathbf{3 0 \%}$ SE & $\mathbf{5 0 \%}$ SE & $\mathbf{8 0 \% ~ S E}$ \\
\hline Current [A] & 0.421 & 0.42 & 0.43 & 0.43 & 0.44 \\
\hline Error[\%] & - & 0.49 & 1.36 & 3.04 & 4.9 \\
\hline
\end{tabular}

Table 4. Torque values for healthy and eccentric conditions

\begin{tabular}{lccccc}
\hline & \multicolumn{5}{c}{ Fundamental Component } \\
\cline { 2 - 6 } & Healthy & $\mathbf{1 0 \%}$ SE & $\mathbf{3 0 \%}$ SE & $\mathbf{5 0 \% ~ S E ~}$ & $\mathbf{8 0 \% ~ S E}$ \\
\hline Torque [Nm] & 14.976 & 14.978 & 14.98 & 14.985 & 14.995 \\
\hline Error[\%] & - & 0.013 & 0.026 & 0.06 & 0.126 \\
\hline & \multicolumn{5}{c}{ Harmonic Components } \\
\cline { 2 - 6 } & Healthy & $\mathbf{1 0 \%}$ SE & $\mathbf{3 0 \% ~ S E}$ & $\mathbf{5 0 \% ~ S E}$ & $\mathbf{8 0 \% ~ S E}$ \\
\hline Torque [Nm] & 1.748 & 1.759 & 1.780 & 1.795 & 1.883 \\
\hline Error [\%] & - & 0.64 & 1.82 & 2.68 & 7.72 \\
\hline
\end{tabular}

The results are presented in Figure 20 and Table 4.

As the fault condition increased, the effect of the high frequency harmonics on torque signal also increased up to $8 \%$.

\section{Test Results}

The current profile is obtained for the healthy condition in order to compare it to the simulation results. 


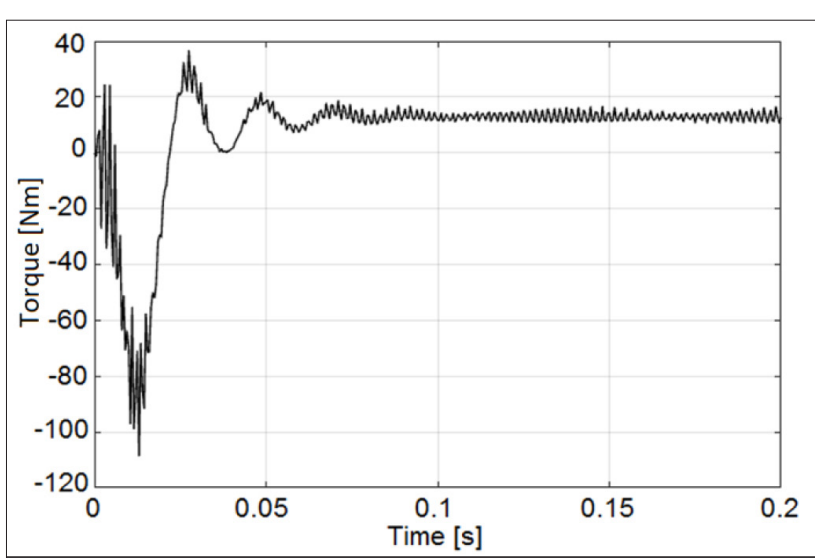

Figure 19. Torque characteristic for healthy condition

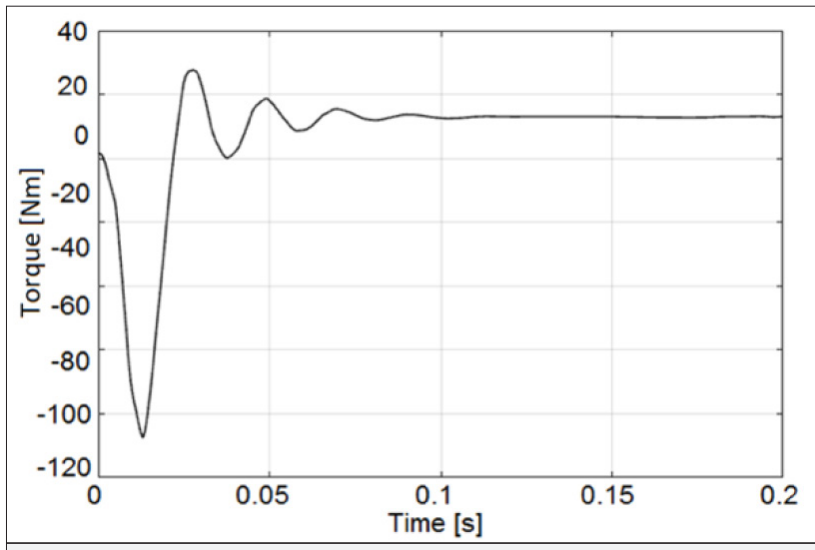

Figure 20. Fundamental component of torque

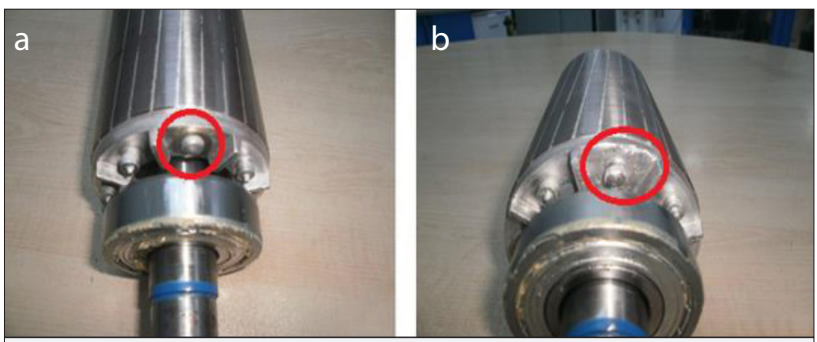

Figure 21. a, b. The rotor of test motor: serial production (a); without bearing balance spacer+ hammered(b); test setup (c)

Table 5. Current test values for healthy and eccentric conditions

\begin{tabular}{llcc}
\hline & & Healthy & Faulty \\
\hline $\begin{array}{l}\text { Fundamental } \\
\text { Component }\end{array}$ & Current [A] & 4.437 & 4.671 \\
\cline { 2 - 4 } & Error [\%] & - & 5.27 \\
\hline \multirow{2}{*}{$\begin{array}{l}\text { Harmonic } \\
\text { Components }\end{array}$} & Current [A] & $\mathbf{0 . 0 2 3}$ & $\mathbf{0 . 0 3 2}$ \\
\cline { 2 - 4 } & Error [\%] & - & 41.1 \\
\hline
\end{tabular}

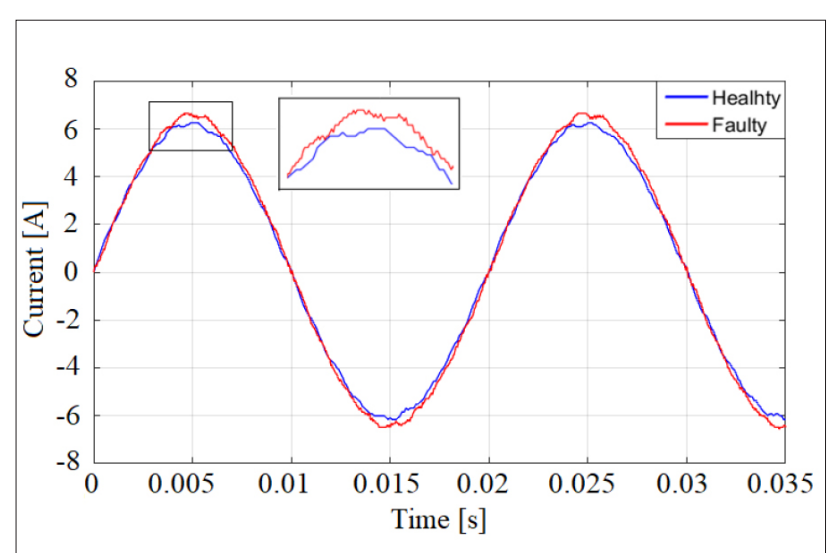

Figure 22. Stator current (test result)

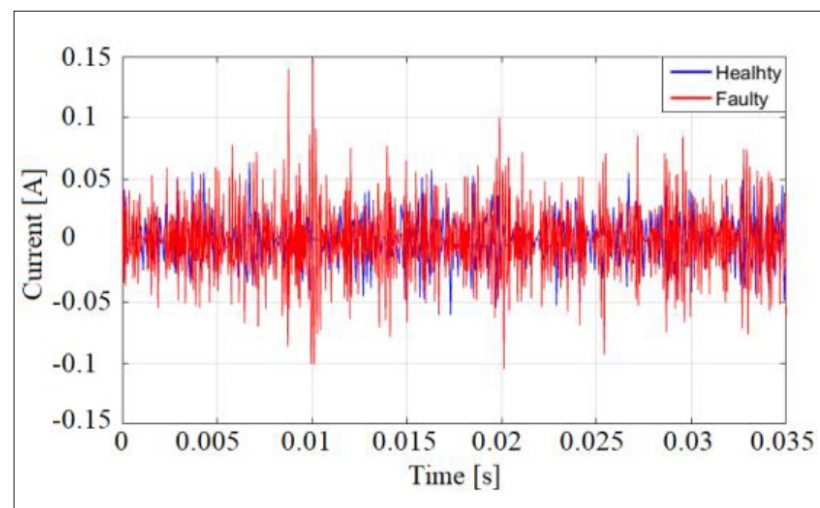

Figure 23. High frequency components of current for healthy and eccentric conditions (test results)

The healthy motor airgap is distorted with a hammer to get a non-uniform rotor surface for the asymmetric conditions. The distorted rotor is given in Figure 21.

The current profiles of the healthy and faulty motor are given in Figure 22.

The high frequency components that could be seen in Figure 23 were decomposed with MRWA. The fundamental components were obtained as shown in Figure 24.

The fundamental and high frequency components of the current show an increasing trend in both the test and simulation results with the faulty condition. The results are given in Table 5.

The vibration values for the healthy and faulty conditions were obtained by experimental setup with an increase of $8.4 \%$ as $0,49 \mathrm{~m} / \mathrm{s}^{2}$ and $0,535 \mathrm{~m} / \mathrm{s}^{2}$, respectively.

High frequency components in the range of $1200-1600 \mathrm{~Hz}$ show a significant difference compared to those of the lower frequency components (Figure 25). The increase trends with the increasing eccentricity in terms of the flux density, current and torque are given in Figure 26. 


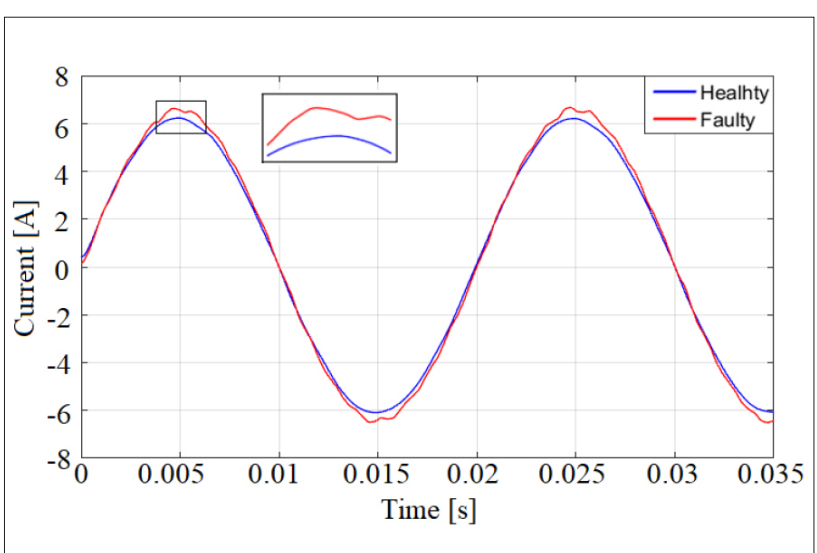

Figure 24. Fundamental components of stator current for healthy and eccentric conditions (test results)

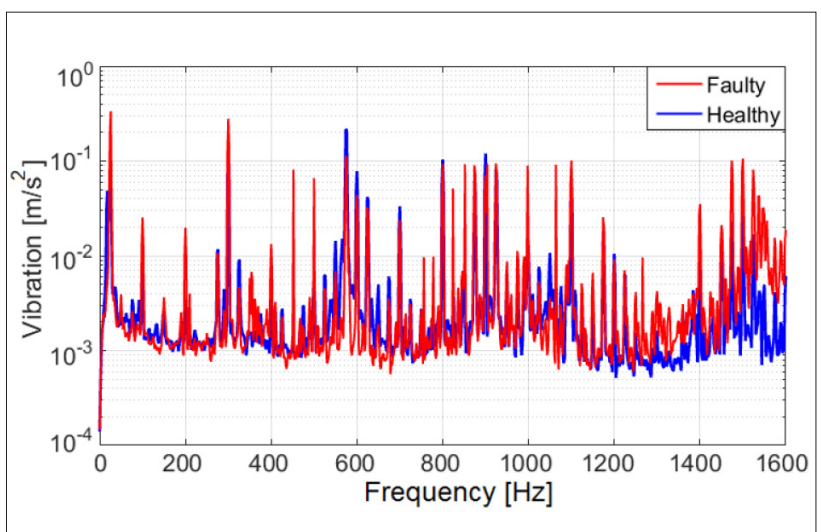

Figure 25. Vibration values on frequency band

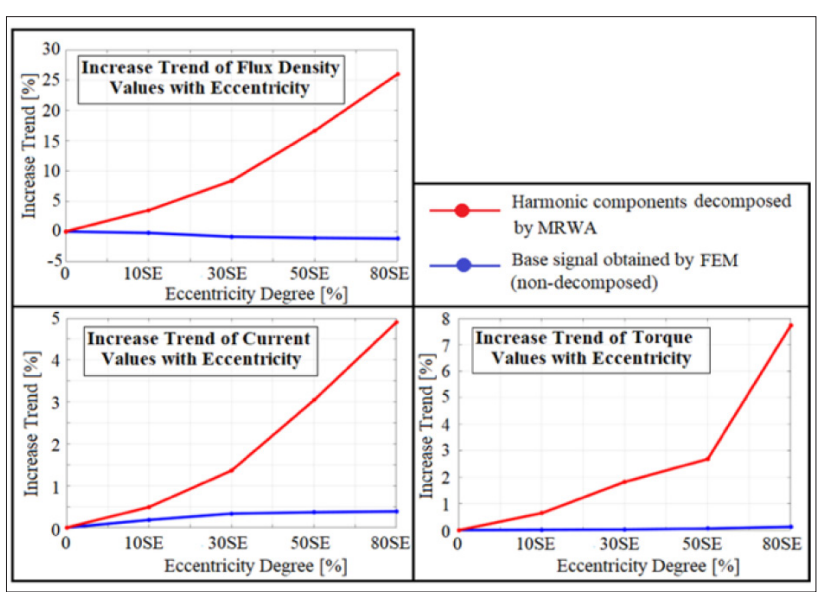

Figure 26. Fundamental components of current for healthy and eccentric conditions (test results)

\section{Conclusion}

In this study, a $2.2 \mathrm{~kW}$ squirrel cage induction motor having different levels of static eccentricity was analyzed by using FEM and MRWA. The healthy motor was also analyzed with FEM and tested to verify the FEM modeling consistency. The air gap flux density, current, torque and vibration parameters were the key parameters used to detect the eccentricity in the motor and these parameters show an increasing trend with increasing air gap eccentricity. The results were decomposed via MRWA and the high frequency components were obtained. The parameters, decomposed by using MRWA, gave more significant information about the increasing fault signal because of the inclusion of the higher frequency components.

The slot harmonics in the flux density, current characteristics and the torque pulsation caused by these harmonics were observed separately from the fundamental component with MRWA. The decomposition of the signal could be seen with wavelet analysis while only the magnitude of harmonic components and harmonic order could be seen with FFT. The results showed that wavelet analysis can potentially be more powerful than FFT in the diagnosis and monitoring of electrical machines.

Peer-review: Externally peer-reviewed.

Acknowledgments: The authors would like to thank Arçelik AŞ Çerkezköy Motor Plant Team Leader Hakan Gedik, MSc,EE for his support in completing the tests of the motor.

Conflict of Interest: The authors have no conflicts of interest to declare.

Financial Disclosure: The authors declared that this study has received no financial support.

\section{References}

1. G.M. Joksimovic, M.Duvoric, J. Penman, N. Arthur, “Dynamic simulation of dynamic eccentricity in induction machines - Winding Function Approach", IEEE Transaction on. 143- 148.

2. S. Nandi, R. M. Bharadwaj, H. A. Toliyat, "Mixed Eccentricity in Three Phase İnduction Machines: Analysis, Simulation and Experiments", Industry Applications Conference, 2002, pp. 1525-1532.

3. A. Polat, Y.D. Ertuğrul, L.T. Ergene, "Static, Dynamic and Mixed Eccentricity of Induction Motor", IEEE International Symposium on Diagnostics for Electric Machines, Power Electronics and Drives, 2015, pp. 284-288.

4. A. J. Ellison, S. J. Yang, "Effects of rotor eccentricity on acoustic noise from induction machines", Proc. IEE, vol. 118, no. 1, 1971, pp. 174-184.

5. S. P. Verma and R. Natarajan, "Effects of eccentricity in induction motors", Proceedings of International Conference on Electrical Machines, vol. 3, 1982, pp. 930-933.

6. A. C. Smith, D. G. Dorrell, "Calculation and measurement of unbalanced magnetic pull in cage induction motors with eccentric rotors. Part 1: Analytical model", IEE Proc. Electr.Power Appl, vol. 143, no. 3, 1996, pp. 193-201.

7. J. R. Cameron, W. T. Thomson, A. B. Dow, "Vibration and current monitoring for detecting airgap eccentricity in large induction motors", IEE Proceedings B Electric Power Applications, vol. 133, no.3, 1986, pp. 155-163.

8. S. Salon, K. Sivasubramaniam, L.T. Ergene, "The Effect of Asymmetry on Torque in Permanent Magnet Motors", The Proceedings of IEEE International Electric Machines and Drives Conference, 2001, pp. 208-217. 
9. A. Polat, Y.D. Ertuğrul, L.T. Ergene, "Analysis of Static Eccentricity in Squirrel Cage Induction Motors", The Proceedings of IEEE International Conference on Power Engineering Energy and Electrical Drives, 2013, pp. 1504-1508.

11. S. Nandi, S. Ahmed, H.A. Toliyat, "Detection of Rotor Slot and Other Eccentricity Related Harmonics in a Three Phase Induction Motor with Different Rotor Cages, IEEE Transactions on Energy Conversion, vol. 16, no. 3, 2001, pp. 253-260.

12. P. Frauman, A. Burakov, A. Arkkio, "Effects of the Slot Harmonics on the Unbalanced Magnetic Pull in an Induction Motor With an Eccentric Rotor, IEEE Transactions on Magnetics, vol. 43, No. 8, 2007, pp. 3441-3444.

13. Z. Chen, J. Meng, B. Liang, D. Guo, "Fault Diagnosis of AC Squirrel-cage Asynchronous Motors based on Wavelet Packet-Neural Network", EUROCON, 2007.

14. H. Bae, Y.T. Kim, S.H. Lee, S. Kim, "Fault Diagnostic of Induction Motors for Equipment Reliability and Health Maintenance Based upon Fourier and Wavelet Analysis", Artifical Life and Robotics, vol.9, no. 3, 2005, pp.112-116.

15. A. Bouzida, O. Touhami, R. Ibtiouen, A. Belouchrani, M. Fadel, A. Rezzoug, "Fault Diagnosis in Industrial Induction Machines Through Discrete Wavelet Transform", IEEE Transactions on Industrial Electronics, vol. 58, no. 9, 2011, pp. 4385-4395.

16. S.G. Mallat, "A Theory for Multiresolution Signal Decomposition: The Wavelet Representation", IEEE, 1989.

17. I.P. Georgokopuolos, E.D. Mitronikas, A.N. Safacas, I.P. Tsoumas, "Detection of Eccentricity in Inverter-Fed Induction Machines using Wavelet Analysis of the Stator Current", IEEE Power Electronics Specialists Conference, 2008.
18. J. Seshadrinath, B. Singh, B.K. Panigrahi, "Single-Turn Fault Detection in Induction Machine Using Complex-Wavelet-Based Method", IEEE Transactions on Industry Applications, vol. 48, no. 6 , 2012, pp. 1846-1854.

19. G.A. Jimenez, A.O. Munoz, M.A. Duarte-Mermoud "Fault detection in induction motors using hilbert and wavelet transforms", Electrical Engineering, vol.89, no. 3, 2007,pp. 205-220.

20. J.P. Llinares, J.A. Daviu, J.R. Folch, D.M. Sotelo, O.D. Perez, "Eccentricity Diagnosis in Inverter - Fed Induction Motors via the Analytic Wavelet Transform of Transient Currents", IEEE International Conference on Electrical Machines, 2010.

21. E. Ayaz, A. Öztürk, S. Şeker, "Continuous Wavelet Transform for Bearing Damage Detection in Electric Motors, MELECON- IEEE Mediterranean Electrotechnical Conference, 2006, pp. 1130-1133.

22. D. Bayram, S. Şeker, "Wavelet Based Neuro-Detector for Low Frequencies of Vibration Signals in Electric Motors", Applied Soft Computing, vol.13, no. 5, 2013, pp. 2683-2691.

23. J. Rosero, J.L. Romeral, J. Cusida, J. A. Ortega, A. Garcia, "Fault Detection of Eccentricity and Bearing Damage in a PMSM by means of Wavelet Transforms Decomposition of the Stator Current", IEEE Applied Power Electronics Conference and Exposition, 2008, pp. 1048-2334.

24. N. Bianchi, "Electrical Machine Analysis Using Finite Elements", CRC Press, Taylor \& Francis Group, 2005.

25. C. Yılmaz, M. İşcan, A. Yılmaz, "A Fully Automatic Novel Method to Determine QT Interval Based on Continuous Wavelet Transform", IU - JEEE, vol. 17, no. 1, 2017, pp. 3093-3099.

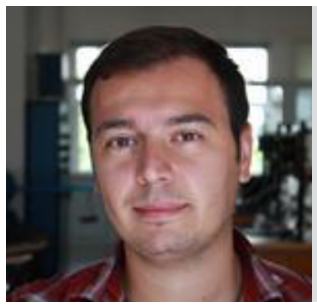

Abdullah Polat received the B.S. and M.S. degrees in Electrical Engineering from Istanbul Technical University, Istanbul, Turkey in 2010 and 2013, respectively. He is currently a Ph.D. student and work as a research assistant at the same department. His current research interests include the design, analysis, control and diagnostic of electrical machines, optimization methods and renewable energy technologies.

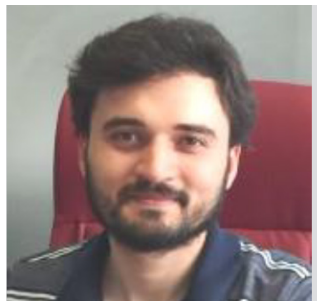

Abdurrahman Yılmaz was born in Muğla. He received bachelors degree from Istanbul Technical University (ITU) Electronics Engineering Program in 2014. At the beginning of 2011, he also enrolled Control \& Automation Engineering by means of double major program. Before graduation, he has started to work for "ASELSAN" which is the biggest defense industry company in Turkey. He currently works as a research assistant at Control \& Automation Engineering Department in ITU, and he is also a Ph.D. student at the same department. His current research areas include interpretation of ECG signals and applications of mobile robotics.

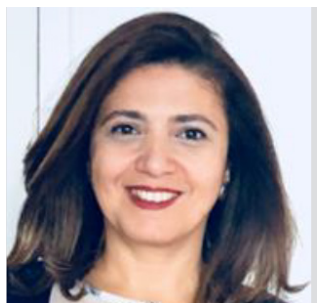

Lale T. Ergene received her BS and M.Sc. degrees in Electrical Engineering at Istanbul Technical University (ITU) in 1992 and 1995 respectively and Ph.D. degree in Electrical Power Engineering at Rensselaer Polytechnic Institute (RPI), NY, USA in 2003. She worked as consultant engineer at MAGSOFT Corporation during 1999-2004. She was also an adjunct assistant professor at RPI in 2004. From 2004 to 2009, she was an assistant professor at the Informatics Institute, ITU. She joined to the faculty of Electrical Engineering, Istanbul Technical University in 2009. She is currently an associate professor at the same department. Her current research interests include design, analysis, control of electrical machines and alternative energy technologies. 